\title{
Single-step colony assay with autoinduction of scFv expression for the screening of antibody libraries
}

$\overline{\text { Mieko Kato' \& Yoshiro Hanyu }{ }^{\star 2}}$

\section{ABSTRACT}

We present a simple colony assay method for screening antibody libraries based on autoinduction of antibody fragment expression. This protocol eliminates the need for colony size monitoring and a separate induction step for single-chain Fv (scFv) antibody fragment expression. Here, scFvs are expressed in an automatic and timely fashion during the assay, resulting in high yields of positive clones and substantial time savings. The method was used successfully to establish monoclonal scFvs with high affinity and specificity against human IgG.

\section{METHOD SUMMARY}

A simple colony assay protocol with autoinduction of antibody fragment expression is described. The method relies on the timely consumption of glucose to ensure sufficient colony size, and subsequent conversion of lactose to allolactose to induce scFv expression.
KEYWORDS:

colony assay $\cdot$ monoclonal antibody $\cdot \mathrm{scFv} \cdot$ screening

'Bio-Peak Co., Ltd, 584-70 Shimonojo, Takasaki 370-0854 Japan; ${ }^{2}$ Structural Physiology Research Group, Biomedical Research Institute, National Institute of Advanced Industrial Science \& Technology (AIST), 1-7-1 Higashi, Tsukuba 305-8566 Japan; *Author for correspondence: y.hanyu@aist.go.jp

BioTechniques 66: 194-197 (April 2019) 10.2144/btn-2018-0195
Recombinant antibody technology enables the screening of large libraries to generate monoclonal antibodies in a shorter time than conventional methods [1]. Libraries with a vast repertoire and efficient screening are two prerequisites for obtaining monoclonal antibodies with high affinity to the antigen [2,3]. Two approaches for screening currently exist: display strategy and repertoire cloning strategy $[4,5]$.

Phage display is the most common form of display strategy $[6,7]$; however, other display systems also exist. These include yeast display, whereby singlechain variable fragments (scFvs) are displayed on the surface of yeast cells [8]; mRNA display [9]; ribosome display, which integrates a ribosome, mRNA and an scFv [10]; bacterial inner-membrane display [11]; and mammalian cell surface display [12] for human antibody discovery. In phage display, antibody fragments are joined to the filamentous phage coat protein $\mathrm{g} 3 \mathrm{p}$. The scFv is suitable as an antibody fragment due to its small size and ease of handling. Panning is performed against the fixed antigen to remove weakly bound clones and is then repeated to select the phage whose scFv exhibits highest affinity to the antigen. This method is characterized by several rounds of selection, proliferation and enrichment of positive clones to enable the processing of large libraries. However, it gives rise to substantial background during panning selection, leading to false-positive clones $[13,14]$.

In the repertoire cloning strategy, antibody libraries, including scFv libraries, are expressed in Escherichia coli, which are grown on a hydrophilic filter placed on an agar plate [15]. Once colonies form, the filter is transferred to an antigen-coated membrane placed on an agar plate containing isopropyl $\beta$-D-1-thiogalactopyranoside (IPTG) to induce scFv production. The scFv produced by the colonies diffuses out, binds to the antigen on the membrane, and its presence is detected by superimposing the spot on the colony (filter-sandwich assay) $[16,17]$. A gene encoding the scFv with affinity for the antigen is obtained. The colony assay identifies clones with high reliability by directly observing antibody-antigen binding, thus resulting in a low false-positive rate. In addition, the method can be easily used to screen libraries an order of magnitude larger than using hybridoma technology [4].

In the filter-sandwich assay, the timing for inducing expression is critical. If induction occurs too early, the stress of expression prevents $E$. coli growth and the resulting colony is too small for the assay. At the same time, E. coli does not express scFv when the colony grows too large $(>1 \mathrm{~mm})$. Therefore, to ensure scFv expression, one needs to carefully monitor colony size and transfer the filter harboring the colonies to the IPTG-containing plate at the right time. This transfer requires delicate manipulation of the filter and frequently causes unwanted stress to $E$. coli. Recently, a singlestep colony assay has been developed, in which the filter is first superimposed on the antigen-coated membrane, the colony is formed on the filter, and the assay can then be performed [18]. This method does not require the filter to be transferred and screening can be completed in a single step. However, it still requires colony size monitoring and a separate induction step. Here, we went a step further by developing an autoinduction protocol that eliminates the need for colony size monitoring and a separate induction step for scFv expression.

The procedure used in the singlestep colony assay with autoinduction is depicted schematically in Figure 1. A hydrophilic polyvinylidene difluoride filter and the antigen-coated nitrocellulose membrane are placed on the agar plate. E. coli transformed with the scFv library are grown to exponential phase and suspended in a solution containing $0.05 \%$ glucose and $0.1 \%$ lactose to inhibit and induce scFv expression, respectively. Then, cells are spread on the filter and 


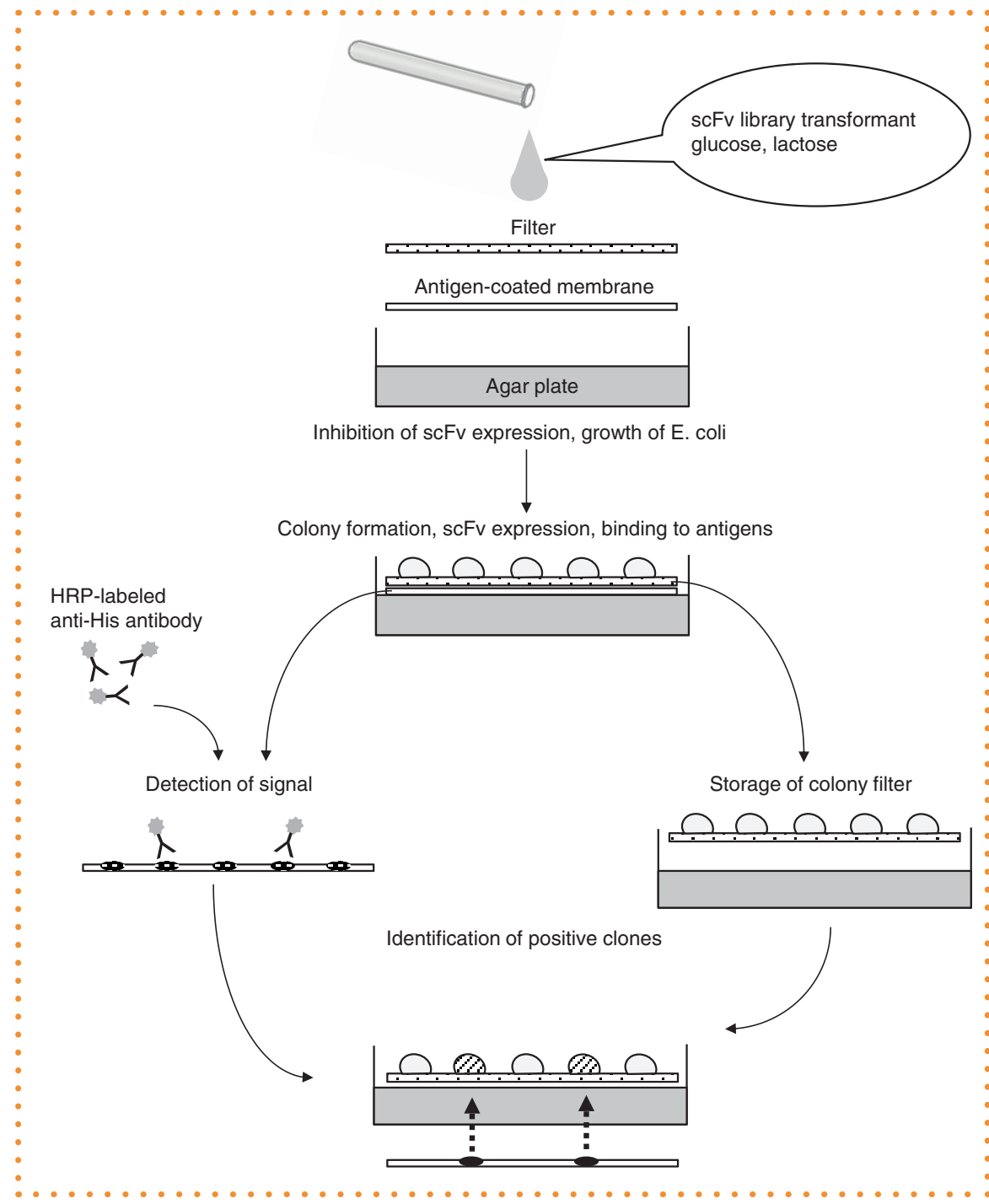

Figure 1. Schematic diagram of the procedure describing the single-step colony assay with autoinduction.

HRP: Horseradish peroxidase; scFv: Single-chain variable fragment.

- incubated. As they consume glucose, E. coli form colonies on the filter surface. Colony size increases as glucose becomes depleted and scFv expression is achieved automatically by subsequent conversion of lactose into allolactose [19]. This simple procedure enables the timely induction of expression using allolactose as the inducer. The scFvs diffuse out into the antigen-coated membrane, where those with affinity bind the antigen beneath the colonies. Importantly, scFvs without affinity do not bind the antigen. The filter with the colonies is removed, placed in a fresh plate, and stored for later recovery of the bacteria. Antigen-bound scFvs on the membrane are detected by chemiluminescence using a horseradish peroxidase
(HRP)-conjugated anti-His antibody. The filter with the colonies and the image with the chemiluminescence data are superimposed. Positive clones corresponding to the chemiluminescence signals are identified, transferred to medium and incubated. Plasmids encoding scFvs with affinity for target antigens are purified.

The single-step colony assay with autoinduction was tested by selecting positive clones from an immune scFv library using human IgG as the antigen (Figure 2). E. coli were transformed with the scFv library and $4 \times 10^{3}$ cells in a solution containing glucose and lactose were spread on a $10-\mathrm{cm}$ plate. Following incubation for $16 \mathrm{~h}$ at $30^{\circ} \mathrm{C}, 3508$ colonies were recorded. Colony diameter varied from 0.5 to $0.8 \mathrm{~mm}$. Colony number and size were almost identical to those on control plates. Antigen binding of scFvs to the lower membrane was detected by chemiluminescence. Spots whose intensity was above 30 (arbitrary units) were considered as positive. In the plate shown in Figure 2, there were 24 such spots. Tight regulation of expression, such as inhibition of leaky expression prior to colony formation (or when the colony size was too small) and induction of expression after colony formation (once the colony was sufficiently large), contributed to the strong signal from positive clones and dispensed with monitoring colony size. This allowed the successful identification of positive clones expressing anti-human IgG scFvs.

20 of the clones with the strongest signal and two clones with no signal were selected for further analysis. Each clone was identified by superimposing the filter and the membrane chemiluminescence image. Cells were picked from the upper filter and cultured to express scFvs. The selected positive and negative clones were cultured at $37^{\circ} \mathrm{C}$ in LB medium containing $50 \mu \mathrm{g} / \mathrm{ml}$ carbenicillin until they reached an OD600 of 0.6. Then, the cells were incubated at $30^{\circ} \mathrm{C}$ for $6 \mathrm{~h}$ in the presence of 1 mM IPTG. Thereafter, they were centrifuged at $5000 \times \mathrm{g}$ at $4^{\circ} \mathrm{C}$ for $5 \mathrm{~min}$, and the supernatants were collected and examined for reactivity against human IgG by ELISA (Figure 3A). Every identified positive clone showed antigen-specific binding activity, whereas no binding to the uncoated ELISA plate blocked with bovine serum albumin was detected. None of the negative clones bound to the antigen or bovine serum albumin. Thus, the colony assay with autoinduction successfully established scFv clones with binding affinity and specificity toward the antigen. The DNA of each scFv from the six clones with the strongest reactivity against the antigen (No. 1, 6, 9, 10, 17, and 18 in Figure 3A) was sequenced. The inferred amino acid sequences of selected clones are shown in Figure 3B. Every clone contained the complete scFv structure consisting of $\mathrm{V}_{\mathrm{H}^{\prime}}$ linker and $V_{L}$. All sequences were unique, indicating that diversity of the scFv library was maintained through the assay. These results show that genes encoding scFvs 
with binding affinity for the antigen could be successfully isolated using our method.

In the filter-sandwich or single-step assays, some bacteria lyse after the assay and colonies cannot be recovered for sequencing. Moreover, clones with an incomplete structure, mainly the omission of $\mathrm{V}_{\mathrm{H}}$, are common [15]. In the colony assay with autoinduction, we did not observe any colony lysis, all positive colonies could be recovered, and all presented a complete structure. Neither inhibition of scFv expression in the early stage of colony formation nor excess scFv expression during the assay seemed to damage $E$. coli cells or the plasmid they harbored. The expression of toxic proteins, such as scFvs, easily leads to lysis of $E$. coli right after plating, when cells are still fragile. In our method, this was prevented by adding glucose to the medium, which inhibited any leaky early expression and allowed the colonies to form. This would explain the high yield of positive clones. Moreover, our method enabled expression to start only after the colony had grown sufficiently, so that all E. coli could express adequate amounts of scFvs. Accordingly, a clear positive signal and the lack of lysis substantially improved the efficiency of screening and the establishment of monoclonal antibodies with binding affinity.

Use of the colony assay to screen antibody libraries poses some drawbacks. As several antibody fragments are toxic to the $E$. coli host, these clones become lost during screening even if they possess high affinity. Conversely, prolonged culturing may result in the preferential propagation of clones with reduced $E$. coli toxicity even if they do not possess high binding capacity. Toxicity to $E$. coli can increase the background, resulting in less efficient screening. Optimization of lactose and glucose concentrations [20], as well as usage of engineered E. coli strains [19], could substantially improve the efficiency of the screening method and avoid the cytotoxicity caused by elevated lactose.

In summary, we report a simple method that does not require colony size monitoring and a separate induction step for scFv expression. Instead, scFvs are expressed in an automatic and timely fashion during the assay.

\section{AUTHOR CONTRIBUTIONS}

YH designed the study and wrote the paper. MK performed the experiments and analyzed the data.

\section{ETHICAL DISCLOSURE}

All animals were cared for and maintained in accordance with the guidelines of the National Institute of Advanced Industrial Science and Technology (AIST).

\section{FINANCIAL \& COMPETING INTERESTS DISCLOSURE}

The authors have no relevant affiliations or financial involvement with any organization or entity with a financial interest in or financial conflict with the subject matter or materials discussed in the manuscript. This includes employment, consultancies, honoraria, stockownership or options, expert testimony, grants or patents received or pending, or royalties.

No writing assistance was utilized in the production of this manuscript.

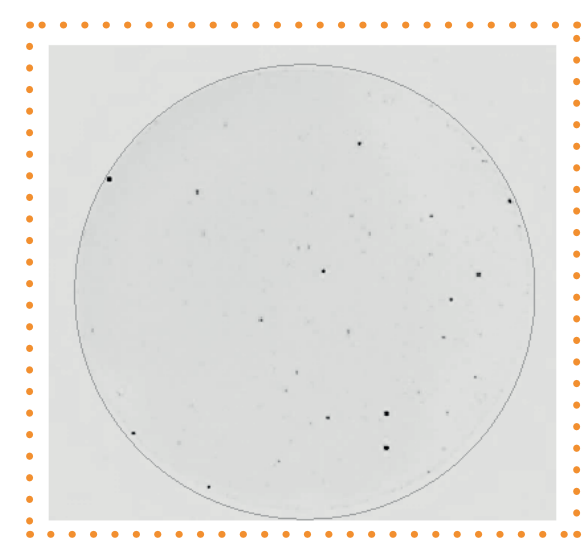

Figure 2. Nitrocellulose membrane image showing positive clones of scFvs against human IgG. Antigen binding of scFvs to the membrane was detected by chemiluminescence. scFv: Single-chain variable fragment.

\section{OPEN ACCESS}

This work is licensed under the AttributionNonCommercial-NoDerivatives 4.0 Unported License. To view a copy of this license, visit http://creativecommons.org/licenses/ by-nc-nd/4.0/

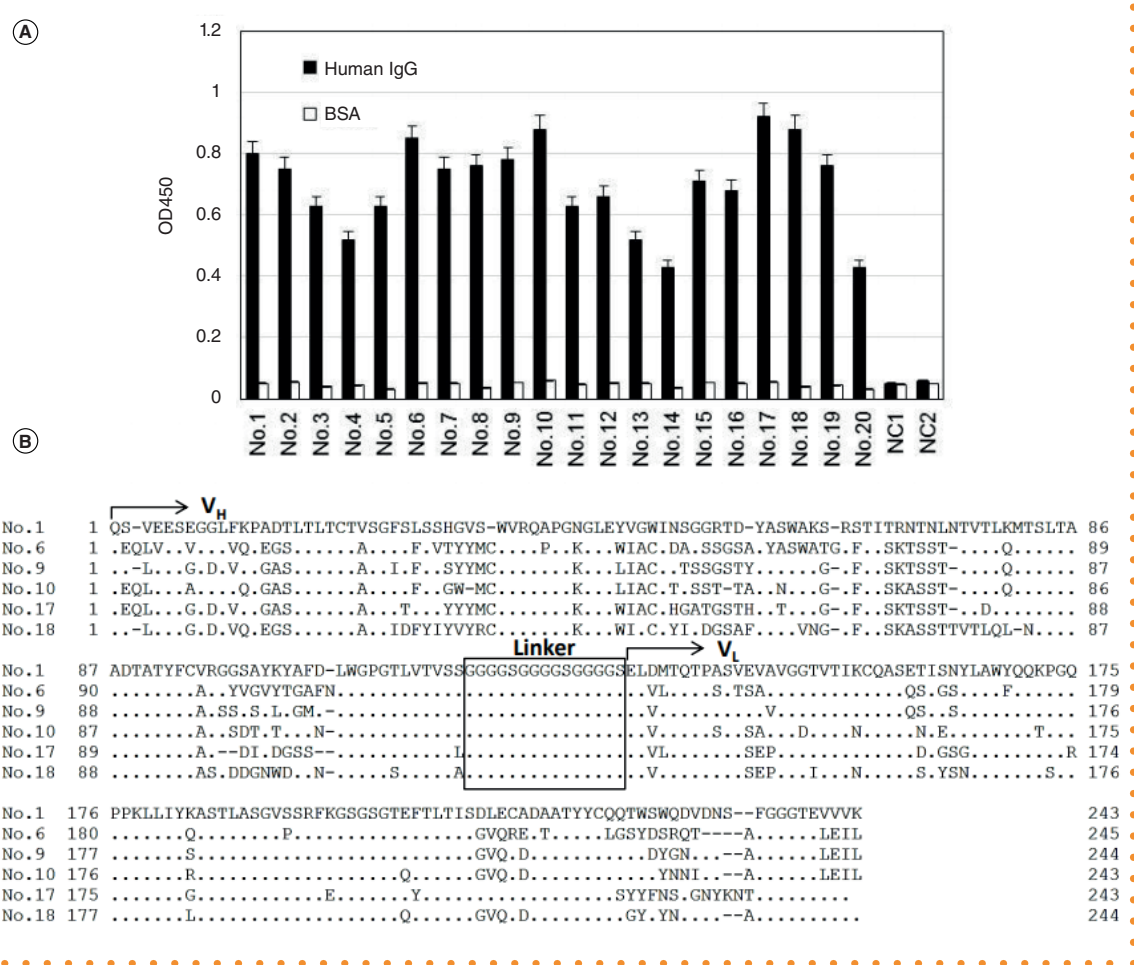

Figure 3. Screening of positive clones from the scFv library obtained by the single-step colony assay with autoinduction. (A) ELISA results showing the reactivity of culture supernatants from 20 positive clones and two negative clones identified in Figure 2 against human IgG and bovine serum albumin (control). Negative clones ( $\mathrm{NC1}$ and $\mathrm{NC2}$ ) were randomly picked from colonies that showed no chemiluminescence signal. Data represent the mean of three replicates; error bars represent the standard deviation. (B) Amino acid sequence alignments of selected clones assayed in Figure $3 A$. $V_{L}, V_{H}$, and linker sequences are shown. Dots and dashes indicate identical amino acids and deletions, respectively. 


\section{- SUPPLEMENTARY DATA}

A supplementary protocol accompanies this paper. To view the supplementary protocol please visit the journal website at: www. future-science.com/doi/suppl/10.2144/ btn-2018-0195

\section{REFERENCES}

1. Geyer CR, McCafferty J, Dübel S, Bradbury ARM, Sidhu SS. Recombinant antibodies and in vitro selection tech nologies. Methods Mol. Biol. 901, 11-32 (2012).

2. Hust M, Frenzel A, Schirrmann T, Dübel S. Selection of recombinant antibodies from antibody gene libraries. Methods Mol. Biol. 1101, 305-320 (2014).

3. Hoogenboom HR. Selecting and screening recombinant antibody libraries. Nat. Biotechnol. 23(9), 1105-1116 (2005).

4. Kato $\mathrm{M}$, Hanyu $\mathrm{Y}$. Screening technologies for recombinant antibody libraries. Med. Res. Arch. 2(7), 12-18 (2015).

5. McCafferty J, Schofield D. Identification of optimal protein binders through the use of large genetically encoded display libraries. Curr. Opin. Chem. Biol. 26, 16-24 (2015)

6. Hammers CM, Stanley JR. Antibody phage display: technique and applications. J. Investig. Dermatol. 134(2), e17 (2014).
7. Schirrmann T, Meyer T, Schütte M, Frenzel A, Hust $M$. Phage display for the generation of antibodies for proteome research, diagnostics and therapy. Molecule (Basel, Switzerland) 16(1), 412-426 (2011).

8. Feldhaus MJ, Siegel RW. Yeast display of antibody fragments: a discovery and characterization platform. $J$. Immunol. Methods 290(1-2), 69-80 (2004).

9. Fukuda I, Kojoh $\mathrm{K}$, Tabata $\mathrm{N}$ et al. In vitro evolution of single-chain antibodies using mRNA display. Nucleic Acids Res. 34(19), e127-e127 (2006).

10. Schaffitzel C, Hanes J, Jermutus L, Plückthun A. Ribosome display: an in vitro method for selection and evolution of antibodies from libraries. J. Immunol. Methods 231(1-2), 119-135 (1999).

11. Moghaddam-Taaheri P, Ikonomova SP, Gong Z, Wisniewski JQ, Karlsson AJ. Bacterial inner-membrane display for screening a library of antibody fragments. JoVE. 116, 54583 (2016).

12. King DJ, Bowers PM, Kehry MR, Horlick RA. Mammalian cell display and somatic hypermutation in vitro for human antibody discovery. Curr. Drug Discov. Technol. 11(1), 56-64 (2014).

13. Matochko WL, Cory Li S, Tang SKY, Derda R. Prospective identification of parasitic sequences in phage display screens. Nucleic Acids Res. 42(3), 1784-1798 (2014).

14. de Wildt RM, Mundy CR, Gorick BD, Tomlinson IM. Antibody arrays for high-throughput screening of antibody-antigen interactions. Nat. Biotechnol. 18(9), 989 (2000).

15. Kato $M$, Hanyu $Y$. Colony assay for antibody library screening: outlook and comparison to display screening. In: Antibody Engineering. Böldicke T (Ed.). InTech, $1-17$ (2018)
16. Rauth S, Schlapschy M, Skerra A. Selection of antibody fragments by means of the filter-sandwich colony screening assay. Kontermann R, Dübel S (Eds). Springe Berlin Heidelberg, 255-266 (2010)

17. Giovannoni L, Viti F, Zardi L, Neri D. Isolation of anti-angiogenesis antibodies from a large combinatorial repertoire by colony filter screening. Nuc. Acids Res. 29(5), e27-e27 (2001).

18. Kato $M$, Hanyu $Y$. Single-step colony assay for screening antibody libraries. J. Biotechnol. 255, 1-8 (2017).

19. Briand L, Marcion G, Kriznik A et al. A self-inducible heterologous protein expression system in Escherichia coli. Sci. Rep. 6, 33037 (2016).

20. Studier FW. Protein production by auto-induction in high-density shaking cultures. Prot. Exp. Purif. 41(1) 207-234 (2005). 